\title{
Welcome to the 9th Volume of Immunotherapy
}

\author{
"Later in 2017, we will be including a special themed issue \\ on allergen immunotherapy and would particularly \\ welcome article proposals in this area."
}

\begin{abstract}
Keywords: allergen immunotherapy • cancer immunotherapy • cancer vaccines $\bullet$ checkpoint inhibitors • immunotherapy
\end{abstract}

\section{Introduction}

I would like to introduce the $9^{\text {th }}$ volume of Immunotherapy and take this opportunity to present some highlights from 2016 and provide some insight into what we have planned for the coming year.

Firstly, I would like to thank all of our valued Editorial Board members, readers and contributors for their continued support; we very much look forward to seeing the journal progress and develop as we move into 2017.

\section{Increased Impact Factor and Issue Frequency}

I am delighted to inform you that this year, the journal witnessed an increase in its impact factor from 2.070 to 2.083 , which is a pleasing accomplishment. In addition, to accommodate the growing number of highquality manuscripts received by the journal, Immunotherapy's frequency will be increasing from 12 issues per year, to 16 issues for 2017 onwards.

\section{Most Accessed Articles from Volume 8}

I have compiled a list of the top 10 most accessed articles from 2016 (Table 1). As this only shows a small number of our most popular articles, I encourage readers to explore the full content from the past year. I would also be delighted to hear which papers have particularly caught your attention and why.

\section{Readership demographic for 2016}

As Figure 1 1illustrates, the journal continues to attract a wide and varied readership, with around a third of our readership being represented by Europe, closely followed by North America and Asia. Since 2014, our readership in North America has more than doubled. This may be attributed to the surge in interest in immunotherapy and the increase in investment by pharmaceutical companies in the USA [11], following major breakthroughs in the field such as four FDAapproved immunotherapies for melanoma treatment since 2011 [12]. Aside from North America and Europe, there has also been a noticeable increase in readers from other parts of the world, including East Asia and Mexico. Immunotherapy looks forward to broadening its global reach and appeal in the coming year.

\section{Special focus issues}

Volume 8 featured special issues covering emerging and increasingly established areas of cancer immunotherapy, in order to shed light on these important areas following recent major breakthroughs in this aspect of the field:

- June - Part I: Checkpoint Inhibitors in Cancer Therapy

- July - Part II: Checkpoint Inhibitors in Cancer Therapy

- November: Cancer Vaccine Clinical Trials

Due to the overwhelming interest, the Checkpoint Inhibitors in Cancer Therapy special issue ran over two insightful issues

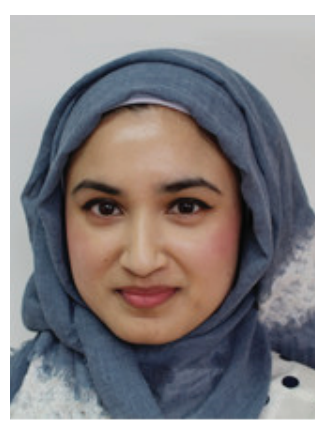

Sonia Mannan

Future Science Group, Unitec House,

2 Albert Place, London, N31QB, UK

s.mannan@futuremedicine.com 
Table 1. Top 10 most accessed Immunotherapy Volume 8 articles (as at 22 November 2016).

\begin{tabular}{|c|c|c|c|c|}
\hline Rank & Title & Authors & Volume (Issue) & Ref. \\
\hline 1 & CAR T-cell therapy: opportunities and challenges & Zhang W & Vol. 8 , No. 3 & [1] \\
\hline 2 & Efficacy of PD-1 blockade in tumors with MMR deficiency & Lee $\mathrm{V}$, Le DT & Vol. 8, No. 1 & [2] \\
\hline 4 & Sarilumab for the treatment of rheumatoid arthritis & Cooper S & Vol. 8, No. 3 & [4] \\
\hline 6 & Part I: Checkpoint inhibitors in cancer therapy & Daud Al & Vol. 8, No. 6 & [6] \\
\hline 7 & $\begin{array}{l}\text { Crisaborole and its potential role in treating atopic } \\
\text { dermatitis: overview of early clinical studies }\end{array}$ & $\begin{array}{l}\text { Zane LT, Chanda S, } \\
\text { Jarnagin K, Nelson DB, } \\
\text { Spelman L, Gold LFS }\end{array}$ & Vol. 8, No. 8 & [7] \\
\hline 8 & $\begin{array}{l}\text { Tremelimumab-associated tumor regression following after } \\
\text { initial progression: two case reports }\end{array}$ & $\begin{array}{l}\text { Shimomura A, Fujiwara Y, } \\
\text { Kond S et al }\end{array}$ & Vol. 8, No. 1 & [8] \\
\hline
\end{tabular}

and covered a range of checkpoint inhibitors that have either been approved, for indications such as renal cell cancer and melanoma, or that have potential therapeutic use (see Immunotherapy Volume 8, issues 6 and 7). The Cancer Vaccine Clinical Trials themed issue explored the latest advances in the field, the status of vaccines that are currently on the market and obstacles in achieving effective cancer vaccine therapy, with the aim of directing the improvement and optimization of future cancer vaccines (see Immunotherapy Volume 8, issues 11).

\section{Spread the word}

The journal has been active on social media through Twitter [13] and LinkedIn [14] so as to provide regular updates on newly published content and the latest news in immunotherapy. We welcome and appreciate all contributions and feedback we receive via these platforms.
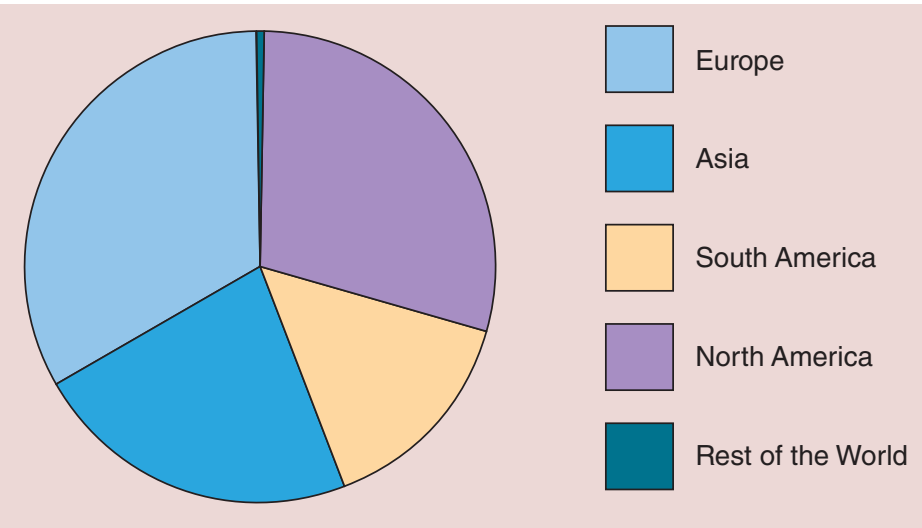

Figure 1. Readership demographics in 2016 for immunotherapy.
Immunotherapy is continuing its partnership with Kudos and we encourage authors to share information about their publications and monitor the impact of their efforts [15].

Immunotherapy also offers accelerated publication and open access options to our authors to increase the speed and reach of their articles. Interested readers can find out more on our website [16].

\section{Conclusion}

We invite and appreciate all feedback from the immunotherapy community on the direction of the field and areas you would like the journal to cover. We also welcome unsolicited article proposals, and would be delighted to hear from you. Later in 2017, we will be including a special themed issue on allergen immunotherapy and would particularly welcome article proposals in this area.

Many thanks for your continuing interest and support for Immunotherapy, I look forward to working with many of you over the coming year.

Financial \& competing interests disclosure

Sonia Mannan is an employee of Future Medicine Ltd. The author has no other relevant affiliations or financial involvement with any organization or entity with a financial interest in or financial conflict with the subject matter or materials discussed in the manuscript apart from those disclosed.

No writing assistance was utilized in the production of this manuscript. 


\section{References}

1 Zhang W. CAR T-cell therapy: opportunities and challenges. Immunotherapy 8(3), 245-247 (2016)

2 Lee V, Le DT. Efficacy of PD-1 blockade in tumors with MMR deficiency. Immunotherapy 8(1), 1-3 (2016)

3 Coffin R. Interview with Robert Coffin, inventor of T-VEC: the first oncolytic immunotherapy approved for the treatment of cancer. Immunotherapy 8(2), 103-106 (2016)

4 Cooper S. Sarilumab for the treatment of rheumatoid arthritis. Immunotherapy 8(3), 249-250 (2016)

$5 \quad$ Kuhn C, Weiner HL. Therapeutic anti-CD3 monoclonal antibodies: from bench to bedside. Immunotherapy 8(8), 889-906 (2016)

6 Daud AI. Part I: Checkpoint inhibitors in cancer therapy. Immunotherapy 8(6), 675-676 (2016)

7 Zane LT, Chanda S, Jarnagin K, Nelson DB, Spelman L, Gold LFS. Crisaborole and its potential role in treating atopic dermatitis: overview of early clinical studies. Immunotherapy 8(8), 853-866 (2016)

8 Shimomura A, Fujiwara Y, Kond S et al. Tremelimumabassociated tumor regression following after initial progression: two case reports. Immunotherapy 8(8), 9-15

(2016)

9 Daud AI. Part II: Checkpoint inhibitors in cancer therapy. Immunotherapy 8(7), 761-762 (2016)

10 Field CS, Hermans IF, Hunn MK. Whole tumor cell vaccines for glioma immunotherapy. Immunotherapy 8(4), 387-389 (2016)

11 Buffery D. The 2015 Oncology Drug Pipeline: Innovation Drives the Race to Cure Cancer. Am. Health Drug Benefits 8(4), 216-222 (2015)

12 Valpione S, Campana LG. Immunotherapy for advanced melanoma: future directions. Immunotherapy 8(2), 199-209 (2016)

13 Immunotherapy Twitter. https://twitter.com/fsgimt

14 Immunotherapy LinkedIn group. https://linkedin.com/ groups/3713578

15 Kudos. https://www.growkudos.com/

16 Future Science Group Publishing Solutions. http://www. future-science-group.com/services/for-professionals/ publication-solutions 
